\title{
EDITORIAL
}

\section{Asymptomatic severe aortic stenosis. ¿ls it better to observe than to operate?}

\author{
Juan H. del Portillo ${ }^{a, *}$, Jaime Camacho ${ }^{b}$, Juan P. Umaña ${ }^{b}$, Jaime Cabrales ${ }^{a}$ \\ a Department of Hemodynamics, Fundación Cardioinfantil, Instituto de Cardiología, Bogotá, Colombia \\ b Department of Cardiovascular Surgery, Fundación Cardioinfantil, Instituto de Cardiología, Bogotá, Colombia
}

Received 19 September 2017; accepted 19 September 2017

Aortic stenosis is the most common primary valvulopathy worldwide. It has an estimated prevalence of 7.6 million people over the age of 75 in Europe and the United States, and the increased life expectancy of the worldis population will cause this rate to continue to increase ${ }^{1}$.

Approximately $50 \%$ of patients are asymptomatic when diagnosed with this valvulopathy, and many may have a preserved ejection fraction (EF). This type of patients has been classified as stage C1, according to the 2014 American Heart Association/American College of Cardiology (AHA/ACC) guidelines. Management consists of clinical and echocardiographic follow-up every six to twelve months (a recommendation made by experts and based on retrospective studies) ${ }^{2}$. However, those with a low surgical risk (score $<4$ according to the Society of Thoracic Surgeons - STS) and who have additional poor prognostic factors such as symptoms triggered by a stress test, severe valve calcification with restricted opening, transvalvular flow velocity $>5 \mathrm{~m} / \mathrm{s}$, mean gradient $>60 \mathrm{~mm} \mathrm{Hg}$, and an increase in valvular flow velocity of more than $0.3 \mathrm{~m} / \mathrm{s} /$ year, benefit from early valve replacement ${ }^{3}$.

DOI of original article:

http://dx.doi.org/10.1016/j.rccar.2017.09.001

* Corresponding author.

E-mail address: drdelportillo@gmail.com (J.H. del Portillo).
Recently, the 2017 AHA/ACC guideline update recommended surgical aortic valve replacement for both symptomatic (stage D) and asymptomatic (stage C) patients with severe aortic stenosis who meet some surgical indication, as long as the surgical risk is low or intermediate ${ }^{3}$. This recommendation could be interpreted in two ways: all patients with severe aortic stenosis, regardless of symptoms, should undergo surgical aortic valve replacement; or asymptomatic patients should have some poor prognostic factor in order to undergo surgery. The latter interpretation is the one that agrees with the 2014 guideline text. For their part, the 2017 European Society of Cardiology guidelines ${ }^{4}$ proposed that observation in patients without poor prognostic factors appears to be safe, while it is unlikely that early surgery would provide a benefit.

\section{What should I know while I observe?}

It is important to remember that the risk of sudden death in these patients is $1-1.5 \%$ per year, and that there are certain factors that make the follow-up strategy difficult, such as the interpretation and variable progression of clinical manifestations, irreversible intrinsic myocardial damage once symptomatology appears, and increased surgical risk with increasing $\mathrm{age}^{5}$. Furthermore, when symptoms begin, the risk of sudden death doubles in the first three to six months, and approximately $6.5 \%$ die waiting for surgical 
aortic valve replacement ${ }^{6}$. This is why other clinical, paraclinical and imaging parameters have been exhaustively studied in recent years: parameters related to a poor prognosis and rapid progression, which may, in turn, help to define the need for early surgical aortic valve replacement in this group of patients during clinical observation ${ }^{5}$ (table 1).

\section{What evidence is there for observing rather than operating?}

A recent meta-analysis compared the conservative strategy to early surgical aortic valve replacement, (defined in only two studies as intervention within three months after diagnosis), and found a risk of mortality due to any cause 3.5 times greater in patients assigned to a conservative strategy ${ }^{5}$. However, a new meta-analysis which compared these two strategies only found a tendency toward lower mortality due to any cause in patients undergoing early surgical aortic valve replacement compared to surgical aortic valve replacement guided by symptoms, with no significant difference in the outcome of death due to cardiovascular causes or sudden death ${ }^{7}$. These meta-analyses are based on observational studies, making it difficult to draw accurate conclusions regarding the best strategy for this group of patients. Thus, the previously mentioned parameters, as well as new individual selection routes based on metabolic

Table 1 Parameters of poor prognosis and rapid progression in patients with asymptomatic severe AS

\begin{tabular}{|c|c|}
\hline Clinical features & $\begin{array}{l}\text { Smoking, Dyslipidaemia, } \\
\text { male gender, diabetes } \\
\text { mellitus, high blood } \\
\text { pressure, chronic kidney } \\
\text { disease, age, cardiac failure } \\
\text { and inactivity }\end{array}$ \\
\hline Abnormal effort test & $\begin{array}{l}\text { Ventricular arrhythmias, } \\
\text { abnormal blood pressure } \\
\text { response and ST segment } \\
\text { depression }\end{array}$ \\
\hline $\begin{array}{c}\text { Echocardiography } \\
\text { parameters }\end{array}$ & $\begin{array}{l}\text { Indexed stroke volume } \\
35 \mathrm{ml} / \mathrm{m}^{2} \\
\text { Dilated left atrium } \\
\text { Left ventricular hypertrophy } \\
\text { and pulmonary hypertension } \\
\text { valvuloarterial impedance } \\
\text { (ZVa) } \\
\text { Global longitudinal strain }\end{array}$ \\
\hline Computerised tomography & $\begin{array}{l}\text { Severe calcification in the } \\
\text { aortic valve }>1274 \mathrm{AU} \\
\text { (Arbitrary Units) in females } \\
\text { and }>2065 \mathrm{AU} \text { in males }\end{array}$ \\
\hline $\begin{array}{l}\text { BNP (Brain natriuretic } \\
\text { peptide) }\end{array}$ & $\begin{array}{l}\text { Prognostic value at rest and } \\
\text { at peak exercise }\end{array}$ \\
\hline
\end{tabular}

"Systolic blood pressure plus mean gradient, divided by stroke volume. Linear relationship between the Zva value and rate of mortality and cardiovascular events in asymptomatic patients (cut-off value from 4.5 to $5.0 \mathrm{~mm} \mathrm{Hg} / \mathrm{ml} / \mathrm{m}^{2}$ )

* Showing subendocardial cardiomyocyte dysfunction secondary to concentric remodelling, subendocardial ischaemia and myocardial fibrosis. needs and fragility, could be a key towards a more objective assessment to help determine the need for early surgical aortic valve replacement.

\section{New routes for follow-up of asymptomatic patients with aortic stenosis}

An individual and integral assessment of these patients should include fragility and basal metabolic rate. Recently, fragility scales have emerged to evaluate candidates for TAVR (transcatheter aortic valve replacement) which could be used to guide the treatment strategy for this group of patients, since the more fragile they are, the easier it will be to decide to just observe them.

Likewise, there are scales that estimate functional capacity, measured in metabolic equivalents (METS), which can be used to estimate the daily activity of asymptomatic patients in their everyday life ${ }^{8}$. In a patient without high metabolic requirements, in whom symptoms will probably not develop, the assessment of other prognostic parameters will possibly not be necessary, and therefore observation and control of clinical risk factors could be sufficient, rather than submitting him/her to an unnecessary surgical risk (fig. 1). However, studies evaluating the usefulness of these variables in the decision algorithm would be necessary.

\section{Pathophysiology of risk factors in aortic stenosis. Should we control them while we observe?}

The concept of the osteogenic process is the key to the pathogenic response to the lesion in fibrocalcifying valvular disease, in which many studies have shown an increased expression of bone morphogenetic protein (BMP), arising from the endothelium of the aortic portion of the valve $^{9}$. These pro-osteogenic processes are guided by direct inhibitors of osteogenic signaling, inflammatory cells, proinflammatory cytokines, angiotensin II, oxidative stress and matrix degrading enzymes, which, in turn, are related to controllable risk factors such as arterial hypertension, diabetes mellitus, hiperlipidemia and smoking ${ }^{10}$. In this sense, knowing beforehand that there is no established medical treatment to prevent disease progression or delay the need for surgical aortic valve replacement, the control of risk factors during a period of observation could at least delay the manifestation of symptoms, which in many contexts appear with decompensation or poor control of the risk factors.

The various interpretations that can be given to the management of patients with asymptomatic severe aortic stenosis and a preserved ejection fraction reflect the fact that there is still no categorical evidence to indicate that early surgical aortic valve replacement is the definitive answer to this question, and show the need to develop and validate new follow-up routes to help define and guide the treatment algorithms. Whether it is better to observe than to operate is still unknown, but what is certain is that individualizing the patient in a context of multidisciplinary management and "heart team̈ could produce better results. 


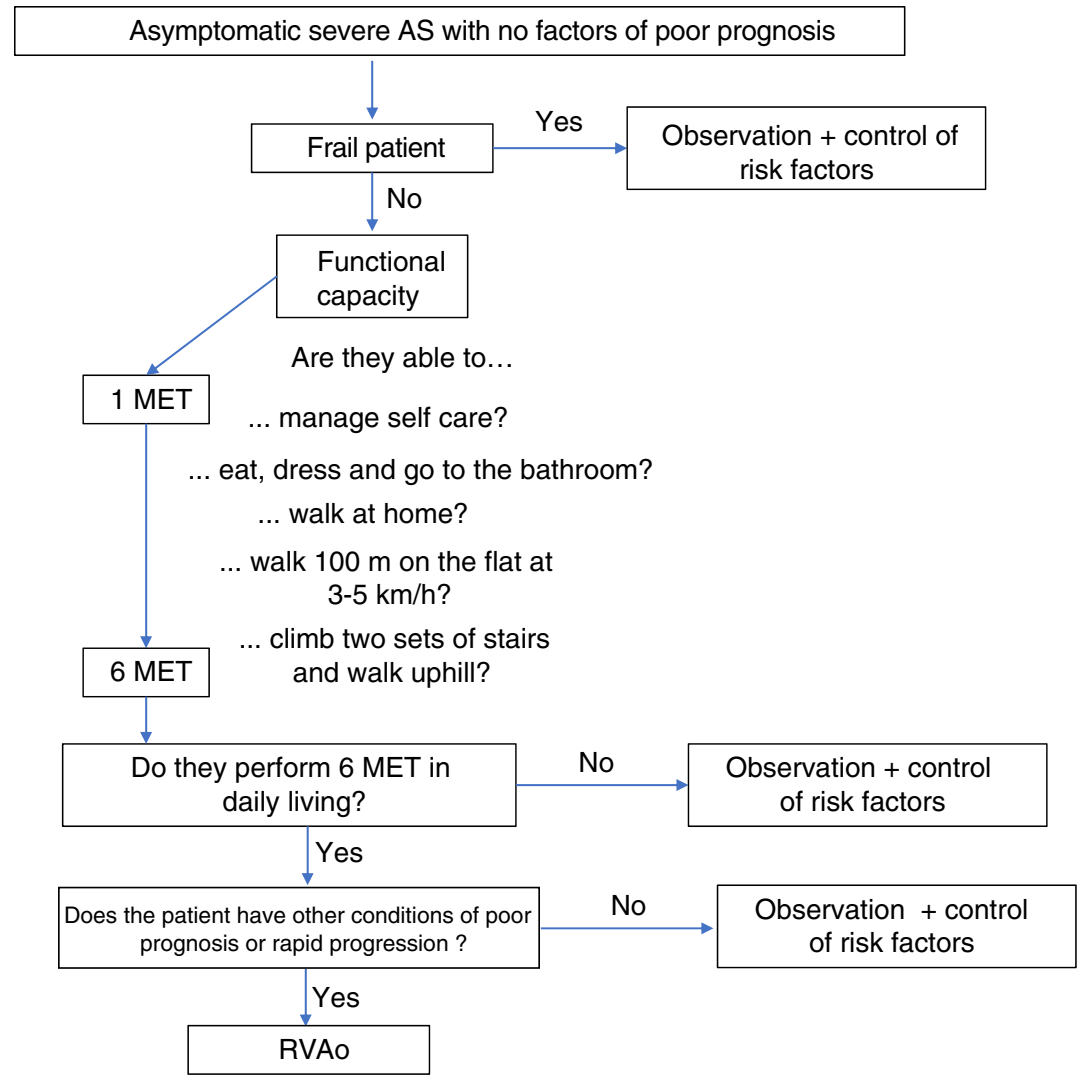

Figure 1 Route for patient's follow-up with asymptomatic severe AS with no factors of poor prognosis.

\section{References}

1. Osnabrugge RLJ, Mylotte D, Head SJ, Van Mieghem NM, Nkomo VT, LeReun CM, et al. Aortic stenosis in the elderly: disease prevalence and number of candidates for transcatheter aortic valve replacement: a meta-analysis and modeling study. J Am Coll Cardiol. 2013;62:1002-12.

2. Nishimura RA, Otto CM, Bonow RO, Carabello BA, Erwin JP, Guyton RA, et al. 2014 AHA/ACC guideline for the management of patients with valvular heart disease: a report of the American College of Cardiology/American Heart Association Task Force on Practice Guidelines. J Am Coll Cardiol. 2014;63: e57-185.

3. Nishimura RA, Otto CM, Bonow RO, Carabello BA, Erwin JP, Fleisher LA, et al. 2017 AHA/ACC Focused Update of the 2014 AHA/ACC Guideline for the Management of Patients With Valvular Heart Disease: A Report of the American College of Cardiology/American Heart Association Task Force on Clinical Practice Guidelines. J Am Coll Cardiol. 2017;70:252-89.

4. Baumgartner $\mathrm{H}$, Falk V, Bax JJ, De Bonis $\mathrm{M}$, Hamm CW, Holm J, et al. 2017. ESC/EACTS Guidelines for the management of valvular heart disease. The Task Force for the Management of Valvular Heart Disease of the European Society of Cardiology (ESC) and the European Association for Cardio-Thoracic Surgery (EACTS). Eur Heart J. 2017:1-53, http://dx.doi.org/10.1093/eurheartj/ehx391.
5. Génereux P, Stone GW, O'Gara PT, Marquis-Gravel G, Redfors B, Giustino G, et al. Natural history, diagnostic approaches, and therapeutic strategies for patients with asymptomatic severe aortic stenosis. J Am Coll Cardiol. 2016;67: 2263-88.

6. Taniguchi T, Morimoto T, Shiomi H, Ando K, Kanamori N, Murata $\mathrm{K}$, et al. Initial surgical versus conservative strategies in patients with asymptomatic severe aortic stenosis. J Am Coll Cardiol. 2015;66:2827-38

7. Lim WY, Ramasamy A, Lloyd G, Bhattacharyya S. Metaanalysis of the impact of intervention versus symptom-driven management in asymptomatic severe aortic stenosis. Heart. 2017;103:268-72.

8. Kristensen SD, Knuuti J, Saraste A, Anker S, Bøtker HE, Hert SD, et al. 2014 ESC/ESA Guidelines on non-cardiac surgery: cardiovascular assessment and management: The Joint Task Force on non-cardiac surgery: cardiovascular assessment and management of the European Society of Cardiology (ESC) and the European Society of Anaesthesiology (ESA). Eur Heart J. 2014; $35: 2383-431$

9. Simmons CA, Grant GR, Manduchi E, Davies PF. Spatial heterogeneity of endothelial phenotypes correlates with side-specific vulnerability to calcification in normal porcine aortic valves. Circ Res. 2005;96:792-9.

10. Catherine M, Otto, Robert O, Bonow. Valvular heart disease: a companion to Braunwald's Heart Disease. $4^{\text {th }}$. Edition Philadelphia, PA: Saunders; 2014. 